\title{
Intestinal Parasitic Infestation: Analysis Over One Year at Shree Birendra Hospital, Chhauni
}

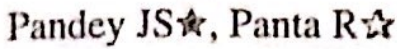

\section{Abstract}

This is a retrospective study of examination of stool for intestinal parasites for the presence of ova, larva and cysts of helminths and protozoa from 1st of Kartik 060 to 30th of Asoj 061 over a span of one year. (Nov 2003 - Oct 2004) During this period a total of 13724 stool samples were received in the laboratory of pathology of Shree Birendra Hospital, Chhauni out of which 1369 , i.e. $9.97 \%$, showed ova, cyst or larva. This study proved that the most common intestinal parasite was Giardia which was positive in 653 cases $(47.69 \%)$ and others were E.hystolytica (15.48\%), Ascaris (14.17\%) and the least prevalent was Strongyloides stercoralis $(0.07 \%)$. Hence, prevalence of protozoa compared to helminths was striking.

This study also showed that regular army personnel (serving) have less parasitic infestation $(6.86 \%$ ) as compared to family which includes wife, children and parents of serving and retired individuals $(12.9 \%)$

The study also shows increased load of stool samples in the months of Baishak, Jestha, Ashad, Shrawan and Bhadra. As the requisition forms were incompletely filled, the particular age group, indication. geographical location and the barracks most affected couldnot be identified. However, information regarding hygiene and sanitation and safe water supply should be assessed and the army should focus on these basic amenities to rectify the problems.

\section{Key words}

Stool sample, helminths, protozoa, families, regular army, hygiene and sanitation.

\section{Introduction}

The incident of intestinal parasites in people with gastroenteritis1, healthy school children2, and

$\star$ Dr. Jagal Singh Pandey, MBBS, MD

Lt. Col., Consultant Pathologist

* Dr. Rajesh Panta, MBBS, MD

Lt. Col., Consultant Pathologist

Head of Department of Pathology

Shree Birendra Hospital, Chhauni pregnant ladies have been reported in many studies. However, overall hospital based studies are very few. Till now, no such study has been carried out in our army hospital. This study is based on both symptomatic and asymptomatic outpatients and inpatients (indications not mentioned in most of the requisition forms) in the army hospital in Kathmandu.

The reservoir of infestation is the carrier or the asymptomatic individual and the mode of transmission is faeco-oral route. The faecal matter contaminates the water and soil. The consumption of contaminated water and food further handled with unclean hands are the major source of infestation. The ova reach the gastrointestinal tract and hatch to start life cycle. When the infective load is very high, damage to the tissue of host starts. Infestation with intestinal roundworms (A. lumbicoides) contributes to the largest group of helminthiasis in human beings. Children are generally more heavily infested and hence are more likely to suffer from pathological consequences of these infestations. Weis EL3 states that infection with Ascaris lumbricoides is rarely fatal but death may occur because of intestinal obstruction. Detection and treatment of asymptomatic carriers of helminths and protozoal parasites is hence of great value to protect their lives.

\section{Material and Methods}

This retrospective study was conducted in Shree Birendra Hospital, Chhauni. All stool samples along with their etiological parasitic agents were noted from the registers of parasitology from 1St of Kartik 060 to 30th of Asoj 061 (Nov. 2003 to October 2004). Specimens were processed for routine microscopic examination. Sterile normal saline was used for emulsification in wet preparation. Iodine preparation was carried out to aid identification when necessary. As the load in the hospital is very high, concentration method was followed only in few highly suspicious samples. The stool samples were examined under a microscope with $10 \mathrm{X}$. The suspected ova, cyst, trophozoites and larva were confirmed by viewing with $40 \mathrm{X}$. 
Results

\begin{tabular}{|l|c|c|c|}
\hline Type of Patients & $\begin{array}{c}\text { Number of } \\
\text { Sample }\end{array}$ & $\begin{array}{c}\text { Number of } \\
\text { Positive Sample }\end{array}$ & $\begin{array}{c}\text { Percentage } \\
\text { Positive Sample }\end{array}$ \\
\hline Family & 7155 & 923 & 12.9 \\
\hline Regular & 6494 & 446 & 6.86 \\
\hline Civil & 38 & 0 & 0 \\
\hline $\begin{array}{l}\text { Police } \\
\text { Including Armed Police) }\end{array}$ & 37 & 0 & 0 \\
\hline Total & $\mathbf{1 3 7 2 4}$ & $\mathbf{1 3 6 9}$ & \\
\hline
\end{tabular}

Table No. 1: Showing total Positive Stool Sample in Different Groups

The above table shows that family members comprise the largest group of patients who require stoo] examination (7155) and $12.9 \%$ of their stool samples are positive for parasites.

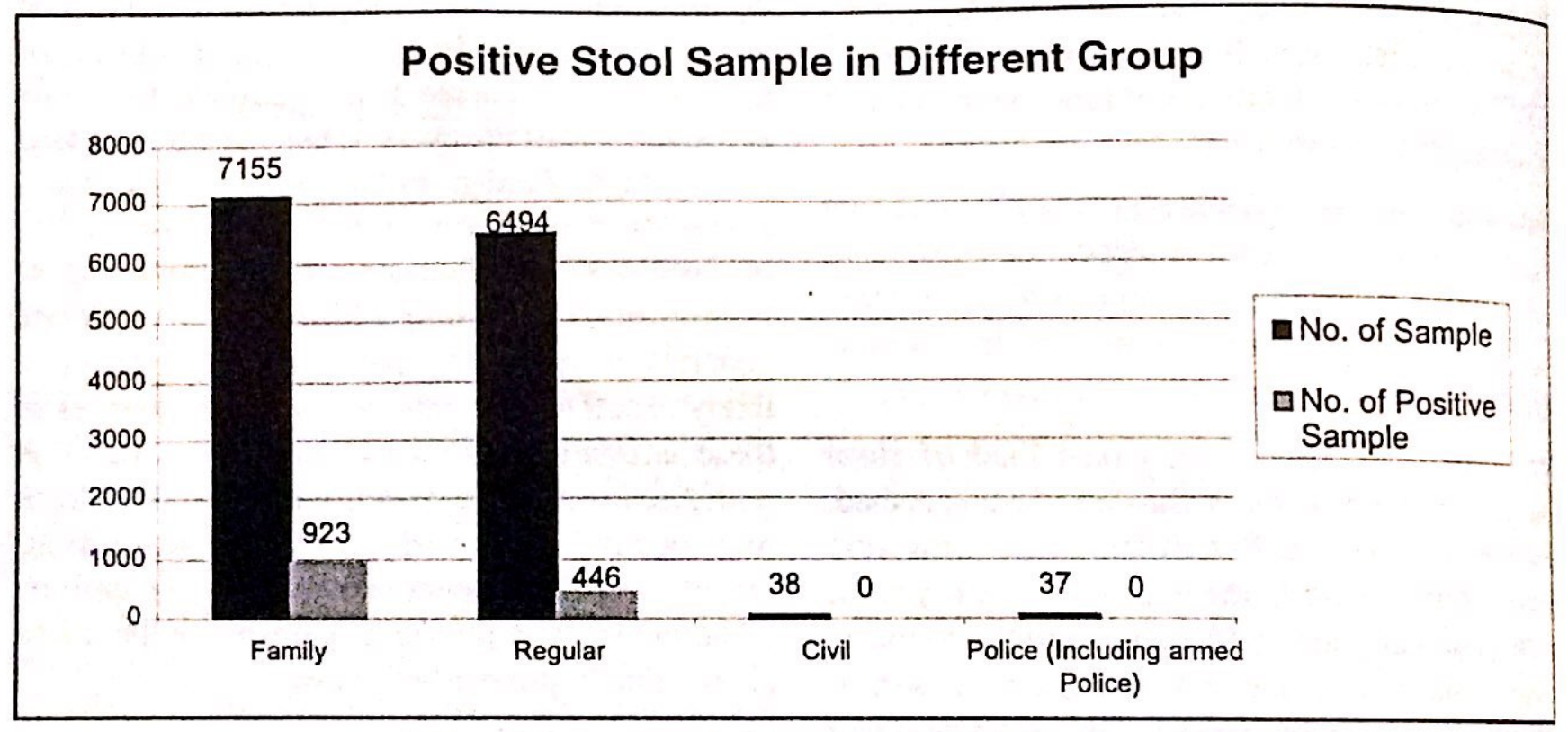

Chart No. 1: Showing Positive Stool Sample in Different Groups

\begin{tabular}{|l|c|c|c|}
\hline Type of Employment & $\begin{array}{c}\text { Total Number of } \\
\text { Sample }\end{array}$ & $\begin{array}{c}\text { Number of Positive } \\
\text { Sample }\end{array}$ & $\begin{array}{c}\text { Percentage } \\
\text { Positive }\end{array}$ \\
\hline Officers & 700 & 58 & 8.28 \\
\hline Non officers & 5794 & 388 & 6.69 \\
\hline Total & $\mathbf{6 4 9 4}$ & $\mathbf{4 4 6}$ & \\
\hline
\end{tabular}

Table No. 2: Showing Parasitic Infestation in Different Groups of Regular Army

The above table depicts that as far as intestinal parasites are concerned, contrary to expectations, officer who have access to better facilities and are thought to be more hygiene conscious, than non-officers at more often victimized by parasites $(8.28 \%)$. 


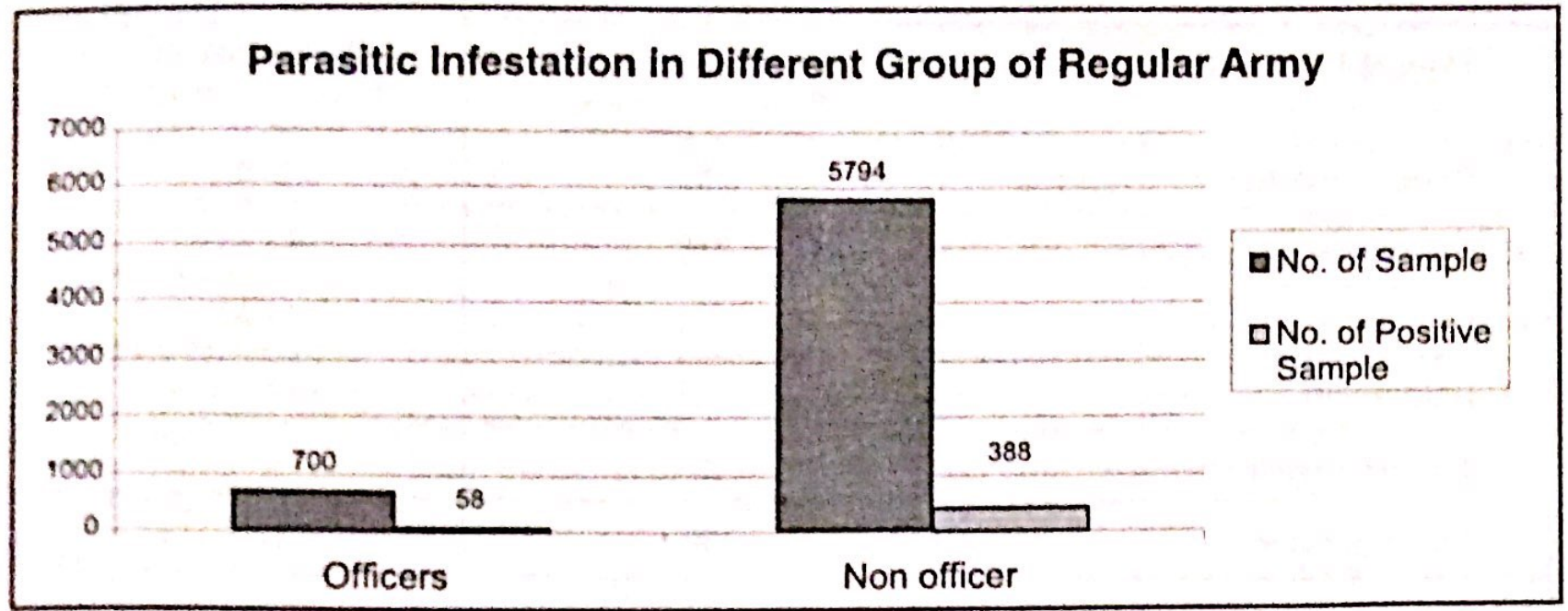

Chart No. 2: Showing Parasitic Infestation in Different Groups of Regular Army

\begin{tabular}{|l|c|c|}
\hline Type of Parasites & $\begin{array}{c}\text { Total Number of } \\
\text { positive Sample }\end{array}$ & $\begin{array}{c}\text { Percentage of } \\
\text { Positive Sample }\end{array}$ \\
\hline Protozoa & 865 & 63.18 \\
\hline Helminths & 480 & 35.06 \\
\hline Mixed & 24 & 1.75 \\
\hline Total & $\mathbf{1 3 6 9}$ & \\
\hline
\end{tabular}

Table Nis, 3 : Showing Broad Groups of Parasites

The tabie no. 3 highlights that protozoal infestation $(63.18 \%)$ is almost double of helminthic $(35.06 \%)$ infestation.

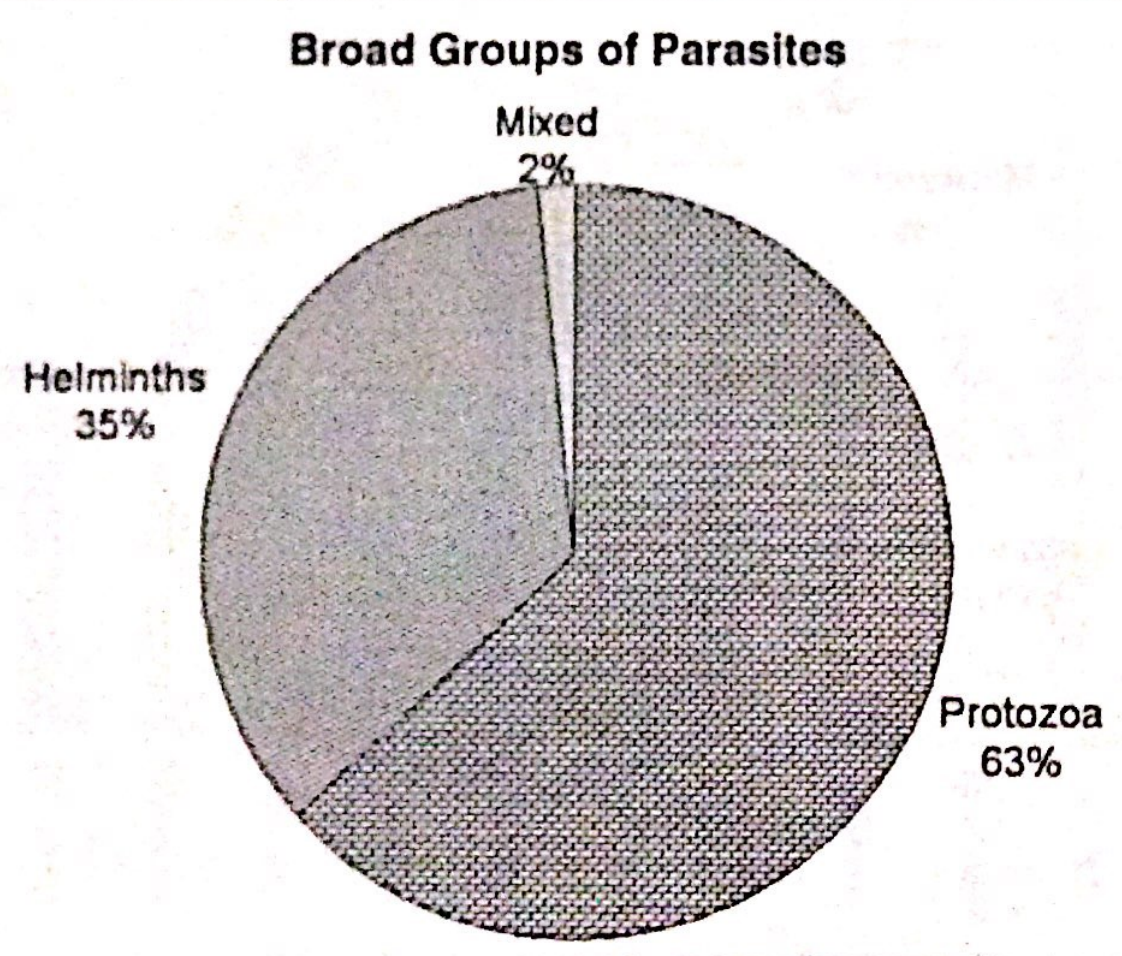

Chart No. 3: Phe Chart Showing Board Group of Parasites 


\begin{tabular}{|l|c|c|}
\hline Type of Parasites & $\begin{array}{c}\text { Total Number of } \\
\text { Positive Sample }\end{array}$ & $\begin{array}{c}\text { Percentage of } \\
\text { Positive Sample }\end{array}$ \\
\hline Giardia lamblia & 653 & 47.69 \\
\hline Entamoeba histolytica & 212 & 15.48 \\
\hline Roundworm & 194 & 14.17 \\
\hline Hookworm & 183 & 13.36 \\
\hline Trichuris Trichuria & 52 & 3.79 \\
\hline Taenia species & 50 & 3.65 \\
\hline Mixed infestation & 24 & 1.7 \\
\hline Strongyloides stercoralis & 1 & 0.07 \\
\hline Total & $\mathbf{1 3 6 9}$ & $\mathbf{1 0 0}$ \\
\hline
\end{tabular}

Table No. 4: Showing Types of Parasites in Stool Sample

Table no. 4 reveals that maximum intestinal parasitism is by protozoa, G. lamblia (47.69\%) and E.histolytica $(15.48 \%)$. Amongst helminths, roundworms and hookworm are the most prevalent $(14.17 \& 13.63 \%$ respectively).

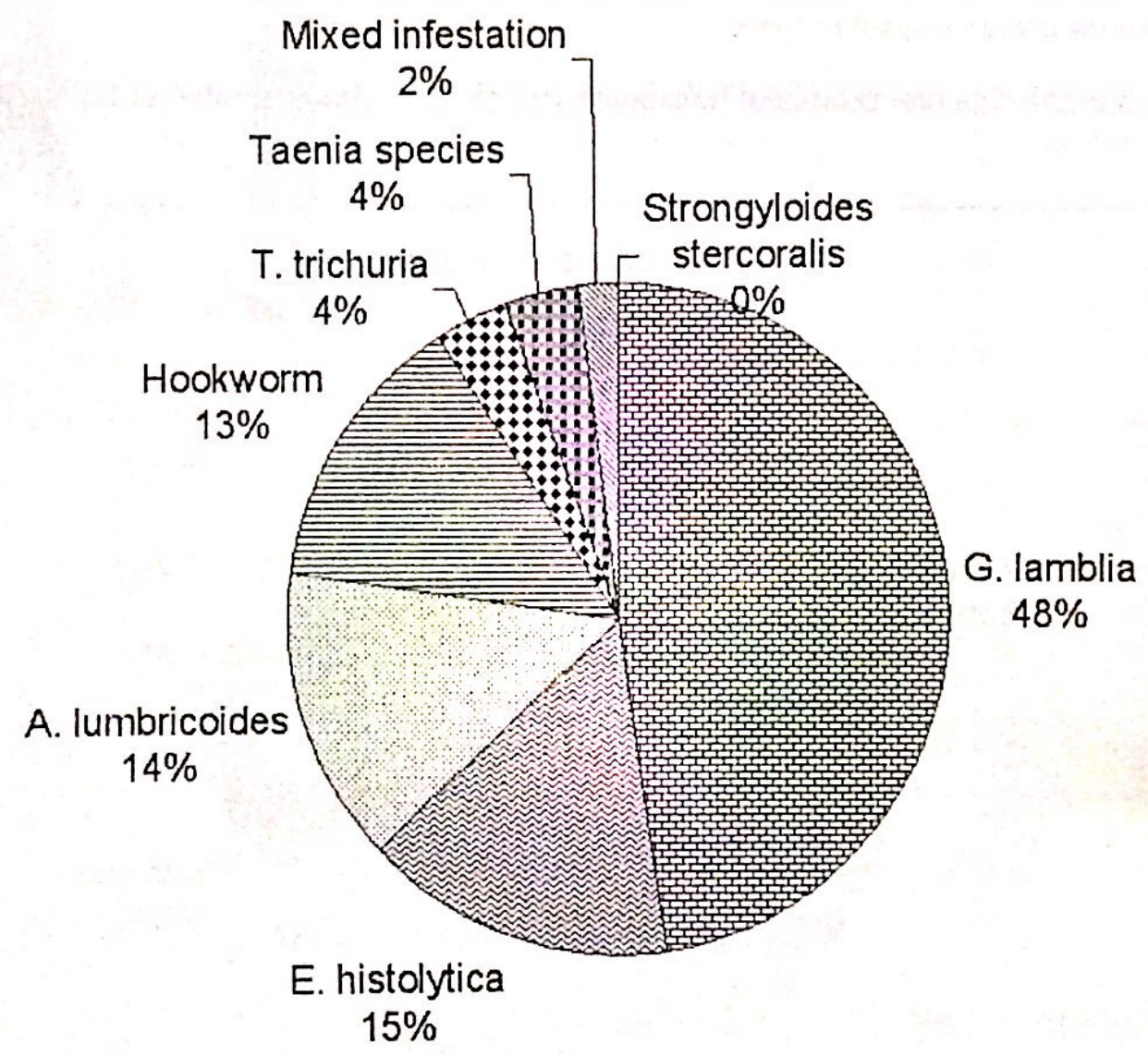

Chart No. 4: Pie Chart Showing Types of Parasites in Stool Sample 


\begin{tabular}{|l|c|c|c|}
\hline Months & $\begin{array}{c}\text { Number of } \\
\text { Samples }\end{array}$ & $\begin{array}{c}\text { Number of } \\
\text { Positive Sample }\end{array}$ & $\begin{array}{c}\text { Percentage of } \\
\text { Positive Sample }\end{array}$ \\
\hline Kartik, 2060 & 957 & 140 & 14.62 \\
\hline Mansir 2060 & 988 & 97 & 9.81 \\
\hline Poush 2060 & 583 & 123 & 21.09 \\
\hline Magha 2060 & 1119 & 114 & 10.18 \\
\hline Falgun 2060 & 680 & 99 & 14.55 \\
\hline Chaitra 2060 & 818 & 63 & 7.7 \\
\hline Baishakh 2061 & 1377 & 168 & 12.2 \\
\hline Jestha 2061 & 1659 & 119 & 7.17 \\
\hline Asadh 2061 & 1429 & 152 & 10.6 \\
\hline Shrawn 2061 & 1577 & 99 & 6.27 \\
\hline Bhadra 2061 & 1596 & 115 & 7.2 \\
\hline Ashoj 2061 & 941 & 52 & 5.52 \\
\hline Total & $\mathbf{1 3 7 2 4}$ & $\mathbf{1 3 6 9}$ & $\mathbf{1 0 0}$ \\
\hline
\end{tabular}

Table No. 5: Showing Distribution of Stool Sample in Different Months and Positivity of the Sample

Table No. 5 verifies stool examination demands were more in months of Baishakh, Jestha, Asadh, Shrawn and Bhadra. However, positive results were seen more often in the months of Poush (21.09\%), Kartik $(14.62 \%)$ and Falgun $(14.55 \%)$.

\section{Distribution of Stool Sample in Different Months and Positivity of the Sample}

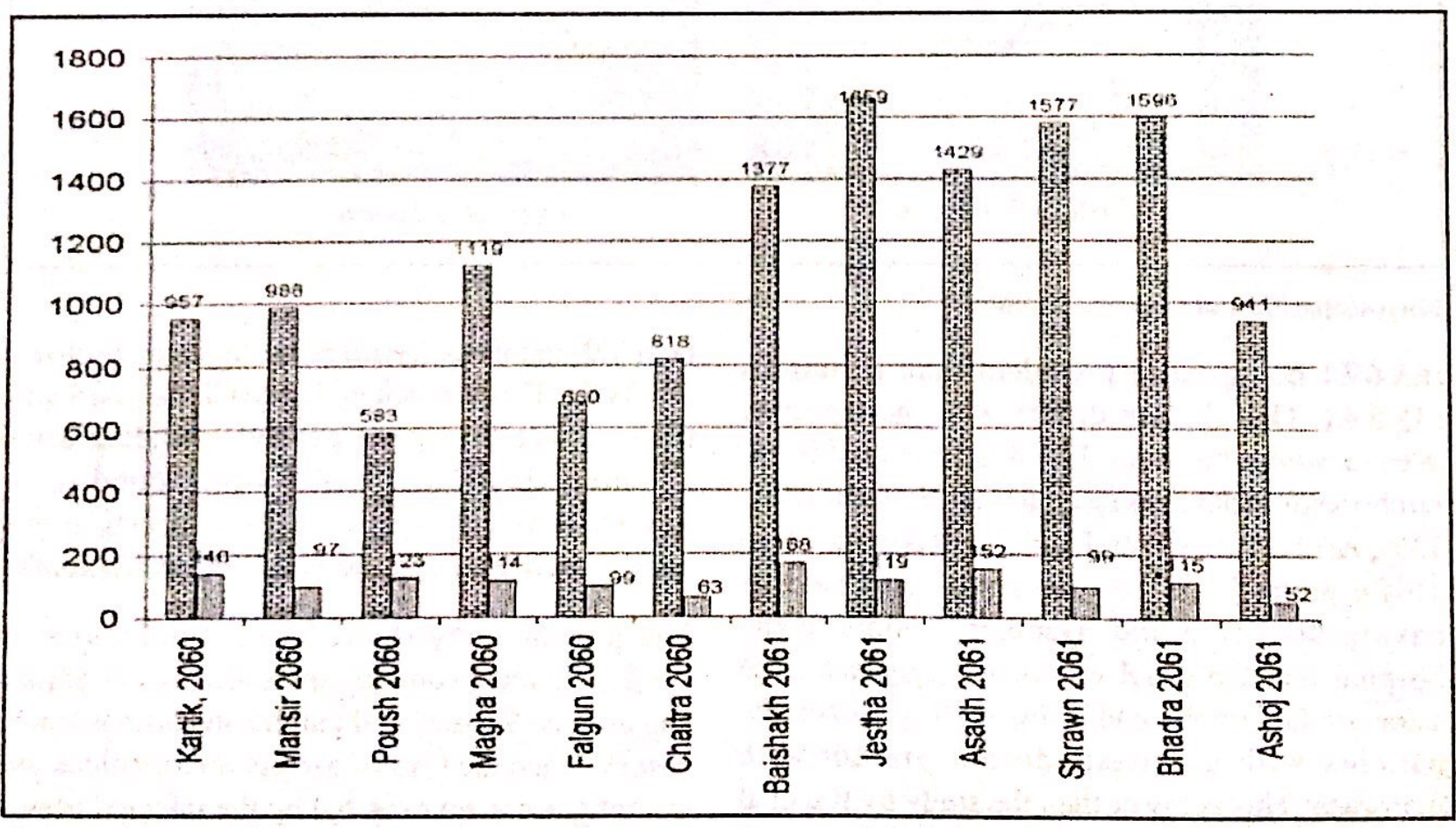

Chart No. 5: Showing Distribution of Stool Sample in Different Months and Positivity of the Sample 


\section{Discussion and conclusion}

This wody of boch out and inpatients showed $9.97 \%$ foople to be infested by parastes. As the wequsition and zeogrontic lompletely filled, age, indication this stody.

Unlike the study of Shrestha B2 in healthy school chilkten of rural area in Lahteur district, which Thow A fumbricoldes infestation in $73.45 \%$ and infestat - present studi reveals highest followed by 5 protozoa, 6 lambla $(47,69 \%)$

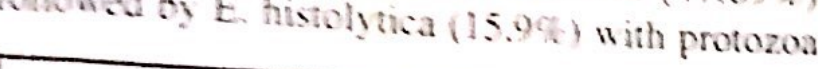
intestinal parasitic protozoa infection among
hospital attending patients secking defection of
intestinal parastes in TU Teaching Hospis intestinal parastes in TU Teaching Hospital to be in the range from $3.3-13.6 \%$. Present stod howed infestation only $14.17 \%$ by roundwat followed by hookworm $(13.36 \%)$. followed h Trehuris trichurta $(3.79 \%)$ and tapeworm $(.36 \%$ This is lower than the study by Thapa. Derkotas and Blangeroo $(36 \%, 30.94 \%$ and $27.24 \%)$ people with gastrointeritis infested wo Alumbricoides. This study is only in partia concurrence with study of Hedge GR, Patel JC which showed $A$. humbricoides as the predominam

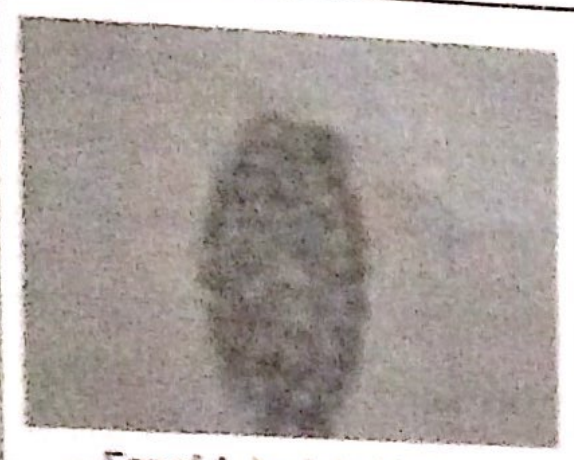

Egg of A tumbricoides (unlertilized)

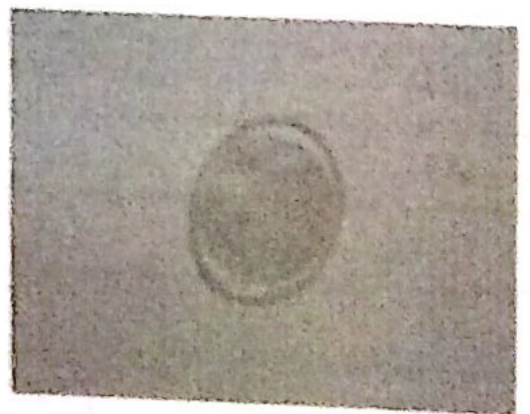

Egg of A lumbricoides (fertilized)

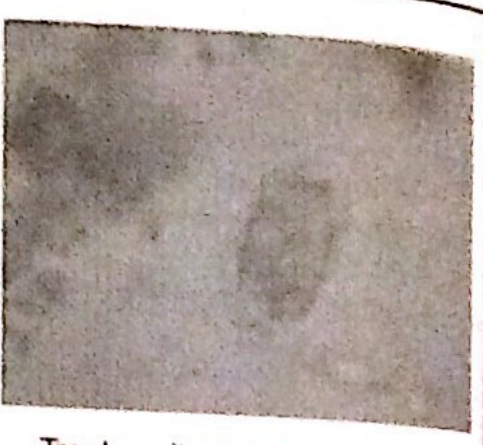

Trophozoites of E. histolytica

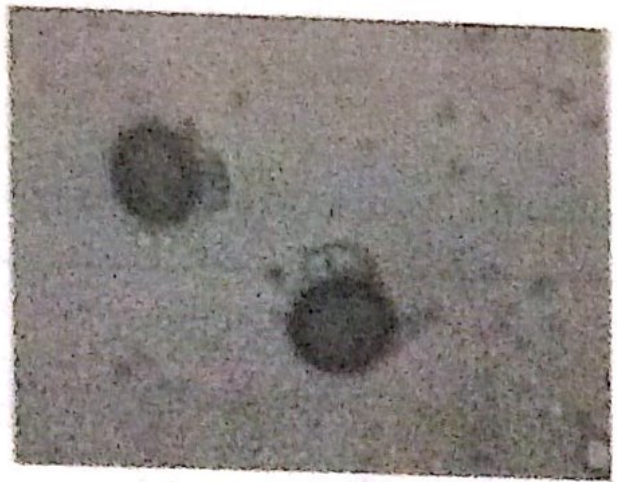

Cysts of E histolytica

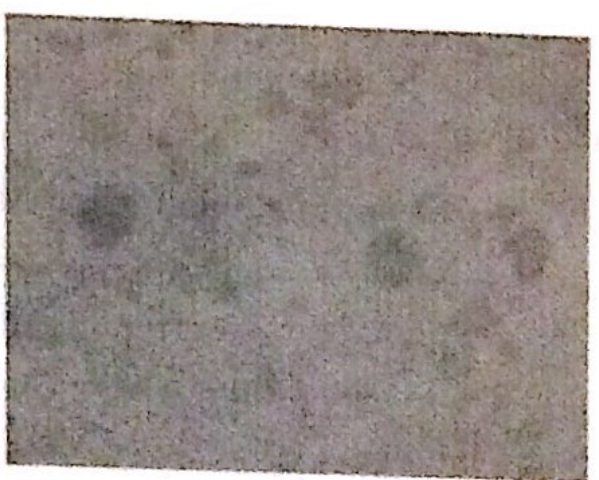

Cysts of G. Lamblia

Magrosicoguc Pictures of sanous parasutes

$(63.6 \%)$ being more prevalent than helminths $(35.5 \%)$. This finding differs with the report of Weiss 3 where he states 1 in 4 are infected by $A$. humbrisonds in developing countries (Southeast Asia $73 \%$. Africa $12 \%$ Central and South America $8 \%$ ) This is probubly because of symptomatic patients having diarthoea and dysentery report to the hospital and the usual etiological agents for the same are G. lamblia and E. histolytica. Generally, patients with ascariasis do not present with diarthoea. This is lower than the study by Rai et al 4 (1994) which reported the annual incidence of helminth and E.histolytica as predominant protozo: $(13.24 \%)$. This is much higher to Chand A BS wh reported that among the patients attending Kant Children Hospital, $27.94 \%$ were found to b infested with pathogenic parasites among whic $16.91 \%$ were protozoa and $11.03 \%$ were helminth

The present study showed mixed infestation if $1.7 \%$. The most common infestation were giard: and ascaris ( 9 cases) and giardia and hook worm cases). Since the Ova of ascaris lumbricoides an cyst of giardia are excreted by the infected perso thus contaminating the soil, water and vegetable 
etc. which when ingested by mouth through contaminated finger, will transmit the disease. Hygiene and sanitation, safe drinking water and proper drainage system should be provided to rectify the parasitic problems. The carriers are the possible source of infestation and hence proper treatment for them is required. They should be advised to treat the water prior to consumption by filtering or boiling or both.

This present study shows that parasitic infestation is a large and serious medical and public health problem in army personnel and their family members. Low level of sanitation, hygiene, water contamination, low standard of health education and bad drainage facilities should be rectified along with proper treatment of carriers to lower down the infestation rate.

\section{Reference:}

1. Sharma AK, Jha N, Ramachandran VG et al. Descriptive epidemioloy of a gastroenteritis out break in Sunrari District, Nepal, JNMA 2002;41:383-387.
2. Shrestha B. Intestinal parasitic infestation in healthy school children of Lalitpur district. JNMA 2001;41:266-270.

3. Weiss E L. Ascaris lumbricoides, eMedicine Journal. 2001;2: No 3

4. Rai S.K. Budhathoki S. Bajracharya K. et al. Prevalence of Intestinal Protozoan Parasitic Infection in Nepal. The Hyogo Journal of Medical Technology. 1994;14: No 4, 39-44.

5. Thapa C.L. Devkota R P. Kaligandaki Hospital; An Example of Community Based Health. JNMA 1991;29:291-300.

6. Blangero $W$ et al. Helminthic infection in Jiri, Nepal. Analysis of age and ethnic group effects; J inst. Med. 1993;15: 210-216.

7. Hedge GR, Patel JC, Prevalence of intestinal parasitic infestation in rural area. J Postgraduate Med 1986;32:225-8

8. Chand A B. Thesis on a Prospective Study on Aetiological Agents of Diarrheal Disease in children in relation to parasites and to Determine the Antibiotic Sensitivity pattern of Isolates. 2000. 